\title{
Investigating the knowledge of the first degree relatives of patients regarding the risk factors and signs of colorectal cancer and colonoscopy screening test
}

\author{
Research Article
}

\section{Seyyed Saeed Mazloomy Mahmoodabad ${ }^{1}$, Marzieh Rafaatmah ${ }^{2 *}$, Aliakbar Vaezi ${ }^{3}$, Seyed Vahid Hosseini ${ }^{4}$}

1. Social determinates of health research center, School of Public Health, Shahid Sadoughi University of Medical Sciences, Yazd, Iran

2. Ph.D. Student of Health Education and Health Promotion,

Shahid Sadoughi University of Medical Sciences and Health Services, Yazd, Iran

3. Associate Professor, Department of Nursing, School of Nursing and Midwifery, Research Center for Nursing and Midwifery Care in Family Health, Shahid Sadoughi University of Medical Sciences, Yazd, Iran

4. Professor of Colorectal Surgery, Colorectal Research Center, Shiraz University of Medical Sciences, Shiraz, Iran

\begin{abstract}
Introduction \& Objective: Colorectal Cancer (CRC) is the third most common cancer in the world. The risk of suffering from colorectal cancer in the first degree relatives is two to eight times higher than the ordinary people of the society. Therefore, the aim of this study is to evaluate the knowledge of the first degree relatives of the clients regarding the risk factors and signs of colorectal cancer and colonoscopy screening tests. Methodology: The present study was a descriptive cross-sectional study. In this study, 116 of the first degree relatives of patients were selected through simple random sampling. A researcher-made questionnaire was utilized to collect information about warning signs and risk factors. The reliability with Cronbach's alpha coefficient $(\alpha=0.70)$ was calculated and then face and content validity were assessed by the professors. Data analysis was performed using SPSS software version 23 and using descriptive statistics (mean, and standard deviation) and inferential statistics (T-test and ANOVA). Results: The level of samples' knowledge about the risk signs of colorectal cancer was higher than the mean level $(36.15 \pm 8.46)$. The highest level of awareness about their (positive / negative) effects on colorectal cancer was related to consumption of vegetables, fruits (2.82 \pm 0.65$)$, and Aspirin consumption $(1.34 \pm 0.62)$. There wasn't a statistically significant difference between age, gender and education with the level of awareness of first degree of relatives but there was significant difference between the occupation of people and the level of awareness $(\mathrm{P}=0.005)$. The level of awareness of first degree of relatives about colonoscopy test was above the average level. $(24.65 \pm 4.57)$. The most knowledge about the nature of colonoscopy $(2.78 \pm 0.52)$ and the least awareness about the vitality of the operation were reported of the people above $50(1.76 \pm 0.74)$. There wasn't a statistically significant difference between the level of awareness of performing the colonoscopy and demographic characteristics of gender, age, education, and occupation. Conclusion: It is necessary to use new methods and strategies to maintain the available status and to raise the awareness of all people in the community regarding the signs and symptoms, especially the use of colorectal cancer screening to manage the initial programs of prevention and treatment.
\end{abstract}

Keywords: Knowledge, First degree relatives, Risk factors and signs, Colorectal cancer, Colonoscopy screening test .

\section{Introduction}

According to the WHO, Iran is in the second of Cancer in the Middle East (1). Colorectal cancer, the second most common cancer among women, and the third common cancer among men is reported in 2012 (2). Among the cancers, after the lung, colorectal and stomach cancers are four of the world's most dangerous and prevalent cancers (3).

The average risk of suffering of colorectal cancer is reported of $5 \%$; after the development, the

*Corresponding Author:

\section{Marzieh Rafatmah,}

International Campus,

Shahid Sadoughi University of Medical Sciences, Yazd, Iran.

Email id: rafatmahm69@gmail.com possibility of emerging of the cancer in the first degree relatives is increased up to 8 times (4). CRC in Iran has also increased in the recent decades (5). However, this is the third popular benign in Iran and it is reported as the second cause of colorectal cancer (6).

This disease is preventable and the rate of recurrence of colorectal cancer is the same among men and women about 50 years old and it is reported among people aged 50 and over it has a relatively high prevalence of this cancer. It is estimated after the age of fifty, 5 to 6 percent of people suffered from this disease (7).

Among the first degree relatives of patients with colorectal cancer, the amount of disease is two to eight times higher than ordinary people in this case the use of colorectal cancer screening to manage the initial programs of prevention and treatment (8). 
Evidence is based on the fact that screening of asymptomatic people, such as first-degree relatives of patients, can detect this cancer at an early stage and can be cured and can reduce the mortality and morbidity of this cancer. But unfortunately, many dependents are not included in screening programs due to lack of awareness about risk factors and screening, low susceptibility to disease, fear of colonoscopy, shameful practices, and lack of under-coverage of insurance (1,4,9-13).

Although screening programs, including primary and curable colonoscopy, are very important, unfortunately, a large number of people at risk are not participating in these programs because of inadequate knowledge $(10,14)$.

A number of studies have shown that people's awareness of signs and risk factors for colorectal cancer is low. Among the results of the study, Power and colleagues showed that people's knowledge about colorectal symptoms and their risk factors is low; thus, the importance of general education in this condition is considered (11). Increasing awareness will also rise the participation of people in screening programs (15). The purpose of this study was to investigate the knowledge of first degree relatives of patients about symptoms, risk factors for colorectal cancer and colonoscopy.

\section{Methodology}

This is a descriptive cross-sectional study. The aim of this study was to determine the awareness of firstdegree relatives of patients in Shiraz about risk factors and signs of colorectal cancer and colonoscopy screening tests. Research setting was referred to Shiraz health clinics and research community was first-degree relatives of patients in Shiraz.

From the total number of first-degree relatives of patients referred to the health centers of Shiraz in 2018, 116 subjects were selected randomly for inclusion in the study.

Criteria for entering the study were first-degree relatives of patients aged 20 to 50 years old or over and non-occurrence of colorectal cancers, and the norms for withdrawal were unwilling to participate in the study. Data gathering tool in this research was a researchermade questionnaire consisting of three parts of which the validity and reliability were confirmed by the researcher.

The first part of the questionnaire related to the characteristics of the individuals of the studied sample units, the second part consists of 25 questions included the awareness of first-degree relatives of patients about the signs and the risk factors, and the third part of the questionnaire, assessed the awareness of people about the colonoscopy test.

The answer points in the questions that are "positive" and "I don't know" are as follows:

Then, the scores were classified in terms of "knowledge level" in three levels of low knowledge, moderate awareness and high awareness, so that in the questionnaire related to the level of awareness of risk factors scores were ranged from 25 to 75 .

In this study, for evaluating the validity of the content, the content validity index CVI and the CVR content validity ratio were used. Ten scholars were hired to determine the validity of the questionnaire, In order to determine the reliability of the questionnaire, modified cases were distributed among 20 individuals of the firstdegree relatives of patients based on Cronbach's alpha; the reliability coefficient related to the knowledge of the subjects was $70 \%$.

The completion of the questionnaires was carried out at a time when the subjects were ready for preparation and they have willingness to participate in the research. Data analysis was performed using SPSS software 23 and using descriptive statistics (mean, standard deviation) and inferential statistics (T-test).

\section{Ethical considerations}

The explanation of the purpose of the research, the freedom of the research unit to participate in the inquiry, the registration of information secretly and without a name, and the research with the permission of the medical authorities of Shiraz is considered in the study.

\section{Result}

In this study, 116 subjects of first-degree relatives of patients were referred to Shiraz health clinics in the age group of 20 to 50 years old, the majority of whom were between 30 and 39 years old $(68.9 \%)$.

Regarding gender $45.7 \%$ (53) was men and 54.3 $\%$ (63) was women, $23.2 \%$ was single and $64 \%$ had university degrees. Other results of the study have shown that $53.4 \%$ was employees and $86.2 \%$ (100) was healthy and $90 \%$ had valid insurance. $84.4 \%$ of the subjects (98) hadn't already performed colonoscopy tests.

According to the results of this study, the awareness level of samples of risk factors of colorectal cancer was higher than the average $(36.15 \pm 8.46)$. Table 1: The mean and standard deviation of response to each of the questions related to awareness of risk factors for colorectal cancer has been reported.

The five risk factors that had the highest level of awareness of the patients (about their positive / negative) on the development of colorectal cancer were related to factors such as consumption of vegetables and fruits $(2.82 \pm 0.65)$, garlic consumption $(2.42 \pm 0.90)$, smoking (2.38 \pm 0.87$)$, exercise $(2.34 \pm 0.93)$ and familial history $(2.34 \pm 0.90)$, and the factors that had the lowest levels of knowledge about their negative/ positive effects were Aspirin consumption (1.34 \pm $0.63)$, Coffee consumption $(1.51 \pm 0.81)$, diabetes $(1.62$ $\pm 0.85)$, B-calcium consumption $(1.75 \pm 0.93)$, and Vitamin D usage $(1.75 \pm 0.94)$.

Table 1: The rate of awareness of risk factors for colorectal cancer

\begin{tabular}{|c|c|c|}
\hline Title & Mean & $\begin{array}{c}\text { Standard } \\
\text { deviation }\end{array}$ \\
\hline Oldness & 2.24 & 9.93 \\
\hline Family history & 2.34 & 0.90 \\
\hline fatness & 2.31 & 0.90 \\
\hline inactive & 2.30 & 0.91 \\
\hline $\begin{array}{c}\text { Coffee } \\
\text { consumption }\end{array}$ & 1.51 & 0.81 \\
\hline
\end{tabular}




\begin{tabular}{|c|c|c|}
\hline Title & Mean & $\begin{array}{c}\text { Standard } \\
\text { deviation }\end{array}$ \\
\hline $\begin{array}{c}\text { Aspirin } \\
\text { consumption }\end{array}$ & 1.34 & 0.62 \\
\hline $\begin{array}{c}\text { Calcium } \\
\text { consumption } \\
\text { material }\end{array}$ & 1.75 & 0.93 \\
\hline Vitamin D & 1.75 & 0.94 \\
\hline garlic & 2.42 & 0.90 \\
\hline nuts & 2.31 & 0.99 \\
\hline $\begin{array}{c}\text { Vegetables and } \\
\text { fruits }\end{array}$ & 2.82 & 0.65 \\
\hline $\begin{array}{c}\text { Alcohol } \\
\text { material }\end{array}$ & 2.25 & 0.94 \\
\hline exercise & 2.34 & 0.93 \\
\hline diabetes & 1.62 & 0.85 \\
\hline Saturated fat & 2.33 & 0.93 \\
\hline Red meat & 2.13 & 0.95 \\
\hline Cigarette & 2.38 & 0.87 \\
\hline \multicolumn{2}{|c|}{}
\end{tabular}

The results indicated that there was no significant difference between men and women in the level of awareness about the risk factors of colorectal cancer. Also, the results of one-way ANOVA did not show a significant difference in the level of awareness of the risk factors of colorectal cancer among different age groups and education. The results showed that employees were significantly more aware of homebased and self-employed people $(\mathrm{P}<0.005)$.

According to obtained result of this study, the awareness level of subjects of warning signs of colorectal cancer was above the average level. (16.05 \pm 4.93). The results showed that the samples were of moderate to low level of awareness of colorectal cancer. Table 2 shows the highest awareness about (positive/ negative) effects on the risk of colorectal cancer is related to the factors of intestinal polyps $(21.2 \pm 0.95)$, intestinal bleeding $(2.18 \pm 0.93)$, and changes in the elimination habits $(2.17 \pm 0.95)$, and the factors that have the least knowledge of their negative/positive effects are gender $(1.59 \pm 0.81)$, unmarkedness $(1.83 \pm$ $0.86)$, unreasonable fatigue was reported $(1.89 \pm 0.91)$.

Table 2: The amount of awareness of risk factors for colorectal cancer

\begin{tabular}{|c|c|c|}
\hline Title & Mean & $\begin{array}{c}\text { Standard } \\
\text { deviation }\end{array}$ \\
\hline Intestinal bleeding & 2.18 & 0.93 \\
\hline $\begin{array}{c}\text { Unreasonable } \\
\text { fatigue }\end{array}$ & 1.89 & 0.91 \\
\hline Intestinal polyps & 2.21 & 0.95 \\
\hline Stomach diseases & 2.04 & 0.97 \\
\hline Weight loss & 2.14 & 0.96 \\
\hline $\begin{array}{c}\text { Changes in the } \\
\text { elimination habits }\end{array}$ & 2.17 & 0.95 \\
\hline Gender & 1.59 & 0.81 \\
\hline Unmarkedness & 1.83 & 0.96 \\
\hline
\end{tabular}

The results showed that there was no significant difference between women and men in the level of knowledge about the symptoms of colorectal cancer. Also, the level of awareness of the symptoms of colorectal cancer in different age groups, education, and occupation was not significant.

In order to assess the awareness of the colonoscopy test, 11 items of the questionnaire were submitted to the sample group, each with three answers "yes", "no" and "I do not know" that were scored from 1 to 3 . The minimum and maximum scores in this index were 11 and 33. According to the results, the mean and standard deviation of the scores were $24.65 \pm 4.57$, indicating an average level of awareness in the firstdegree relatives of patients with colorectal cancer from colonoscopy test.

Table 3 shows that the colonoscopy nature factor (2. $57 \pm 0.52)$, colonoscopy test $(2.72 \pm 0.52)$, and the diagnosis of all intestinal masses $(2.45 \pm 0.87)$ were the most knowledgeable. There is little knowledge about the necessity of colonoscopy in patients over the age of 50 years $(1.76 \pm 0.74)$, painless and uncomplicated $(1.90 \pm 0.75)$ and need to be repeated in the following years $(1.99 \pm 0.82)$ the lowest level of awareness has been reported.

Table 3: The amount of awareness of colonoscopy test

\begin{tabular}{|c|c|c|}
\hline Title & Mean & $\begin{array}{c}\text { Standard } \\
\text { deviation }\end{array}$ \\
\hline Colonoscopy nature factor & 2.78 & 0.52 \\
\hline Colonoscopy test & 2.72 & 0.57 \\
\hline Accurate diagnostic test & 2.37 & 0.91 \\
\hline $\begin{array}{c}\text { Necessity for people over } \\
\text { 50 }\end{array}$ & 1.76 & 0.74 \\
\hline $\begin{array}{c}\text { Observing all intestinal } \\
\text { masses }\end{array}$ & 2.45 & 0.87 \\
\hline $\begin{array}{c}\text { Necessity for first degree } \\
\text { relatives }\end{array}$ & 2.34 & 0.88 \\
\hline Need for all the people & 2.06 & 0.89 \\
\hline $\begin{array}{c}\text { Need of repetition in next } \\
\text { years }\end{array}$ & 1.99 & 0.82 \\
\hline $\begin{array}{c}\text { Painless and } \\
\text { uncomplicated }\end{array}$ & 1.90 & 0.75 \\
\hline Fear of performance & 2.12 & 0.65 \\
\hline Shyness of performance & 2.15 & 0.68 \\
\hline \multicolumn{2}{|c|}{} \\
\hline
\end{tabular}

Independent t-test and One-way ANOVA were used to assess the first-degree relatives of patients and their relationship with demographic characteristics. The results indicated that there was no significant difference in knowledge about colonoscopy testing between different genders, different occupations, different age groups, and education.

\section{Discussion}

The findings of this study showed that the level of awareness of the first-degree relatives of patients towards the risk factors was at the average level.

In a study by Harmy et al. (2011) aimed at assessing patients' knowledge and attitudes towards colorectal screening in western Malaysia, it was 
concluded that the knowledge and attitude of individuals towards high risk factors for colorectal cancer were high and it is consistent with the present study (16). Also, the results of Ghanaei (2015) and Wang (2017) studies are consistent with the present study $(17,18)$.

According to the results of Salimzadeh's study on people at risk of colon cancer, the knowledge of the selected samples of risk factors about colon cancer was low, which is not consistent with the present study (6).

In Cheong et al. (2015), titled a poor knowledge of Colorectal Cancer in Brunei, showed that in women, educated, non-Malay people were more aware, but in general, people had an inadequate level of knowledge about symptoms and risk Colorectal cancer factors were present (19).

According to other results of this study, the highest level of people's knowledge was of five factors like consumption of vegetables and fruits, garlic consumption, smoking, exercise, , and family history. The lowest level of knowledge was related to aspirin usage, coffee consumption, diabetes, and calcium consumption, and vitamin D.

In a study, Harmy et al. (2011) also have found the highest level awareness of the risk factors of a diet without fruits and vegetables and alcohol abuse consistent with the current study (16). In several studies, smoking was also considered as a known risk factor by the majority of people, which coincided with this study $(20-22)$.

Knowing and recognizing the signs of colorectal cancer play an important role in controlling the disease in its early stages and it is early treatment of the disease. Desirable Health education, high publicity activities of mass media, and promotion of general knowledge of physicians and nurses can affect public health and the awareness of clients of signs. This can increase the effectiveness of primary prevention levels for disease control. $(18,23)$

According to another result obtained from this study, the awareness of the colonoscopy screening method was slightly above the average. The samples had the highest awareness about the factor of colonoscopy test nature and they had the lowest awareness about the necessity of testing in the age over 50 .

According to the results of the Ghanaei study (2015) and colleagues, most participants were aware of colonoscopy (18).

In the study of Shouri Bidgoli (2015) aimed at assessing the knowledge, attitude and practice of people over 50 years of age towards screening for colorectal cancer, it was concluded that most participants did not know about colon cancer and its screening, incompatible with the present study (24).

Also, in a study by Woudstra (2016) aimed to measure knowledge, attitude, and beliefs regarding colorectal cancer screening among ethnic minorities in the Netherlands, it was concluded that, while people's attitude towards screening was positive, people's awareness was at a low level with regard to colorectal cancer screening, which was not consistent with the study (25).
The main point of the present study is that despite the average level of awareness among firstdegree relatives of patients with colorectal cancer, only $15.5 \%$ (18 cases) of the samples performed colonoscopy, which indicates the weak level of awareness of the first-degree relatives about the importance of colonoscopy.

Therefore, considering a scheduled program for the strong and effective communication of first-degree relatives of patients with health care centers in order to make people's awareness of the potential state to the actual state of affairs. Regarding the growing trend of colorectal cancer (26.27) in Iran, the risk of first-degree relatives and the reduction in the age of the disease and the need for screening for colorectal cancer by increasing the awareness of people at risk of Symptoms, risk factors and colonoscopy for early diagnosis and rapid treatment are increased.

\section{Conclusion}

Awareness is one of the important factors in predicting health behaviors. However, according to the findings, the level of awareness of the first-degree relatives of patients with colorectal cancer who were considered as high-risk individuals in the community was moderate to high, but lack of screening methods indicated an inadequate knowledge of these individuals. Regarding the increasing trend of colorectal cancer especially in the young population of the society, the implementation of educational programs for managing the primary levels of prevention, screening, and treatment in the community is essential. It is also important to use new methods and strategies to maintain the status quo, as well as to raise the awareness of all people in the community.

\section{Acknowledgments}

The researchers expressed their gratitude to the deputy of the Shiraz University of Medical Sciences, the staffs of the health centers of Shiraz and the people participating in this study.

\section{References}

1. Hirokawa K, Utsuyama M, Kikuchi Y, Kitagawa M. Scoring of immunological vigor: trial assessment of immunological status as a whole for elderly people and cancer patients. Immunosenescence: Springer; 2007. p. 15-23.

2. Cancer IAFRO.world cancer fact sheet geneva switzerland.word health organization. 2012.

3. Levin B, Lieberman DA, McFarland B, Smith RA, Brooks D, Andrews KS, et al. Screening and surveillance for the early detection of colorectal cancer and adenomatous polyps, 2008: a joint guideline from the American Cancer Society, the US Multi-Society Task Force on Colorectal Cancer, and the American College of Radiology. CA: a cancer journal for clinicians. 2008;58(3):130-60.

4. Cancer IAfRo. Colorectal cancer incidence and mortality worldwide in 2008. 2008.

5. Katz ML, Tatum C, Dickinson SL, Murray DM, Long-Foley $\mathrm{K}$, Cooper MR, et al. Improving colorectal cancer screening by using community 
volunteers: results of the Carolinas cancer education and screening (CARES) project. Cancer: Interdisciplinary International Journal of the American Cancer Society. 2007;110(7):1602-10.

6. Pourhosseingholi M, Fazeli Z, Fazeli Bavndpvr F, ABDI A. Study of mortality from colorectal cancer in Iran during 1996-2004. Medical Science Journal of Islamic Azad University. 2013;1:16-20.

7. Rezaianzadeh A, Safarpour AR, Marzban M, Mohaghegh A. A systematic review over the incidence of colorectal cancer in Iran. Annals of colorectal research. 2015;3(1).

8. Islamic Republic of Iran Ministry of Healthand Medical Education Office of Deputy Ministerfor Health Center for disease control cancer offfice. Iranian annual National Cancer Registration Report. 2005-2006.2007 March.

9. Azizi F, Hatami G, Hjnghorbani M. Epidemiology and Control of Common Disorders in Iran. Tehran Publications Khosravi; 2010.

10. Brunner LS. Brunner \& Suddarth's textbook of medical-surgical nursing: Lippincott Williams \& Wilkins; 2010

11. Haggar FA, Boushey RP. Colorectal cancer epidemiology: incidence, mortality, survival, and risk factors. Clinics in colon and rectal surgery. 2009;22(4):191.

12. Longo DL, Fauci AS, Kasper DL, Hauser SL, Jameson JL, Loscalzo J. Harrison's principles of internal medicine 18E Vol 2 EB: McGraw Hill Professional; 2012.

13. Rahimi Pordanjani S, Baeradeh N, Lotfi $M H$, Pourmohammadi B. Epidemiology of colorectal cancer: incidence, mortality, survival rates and risk factors. Razi Journal of Medical Sciences. 2016;23 (144):41-50.

14. Sharifikia I, Rohani C, Estebsari F, Salmani F, Matbouei M, Hossein-nejad A, et al. Awareness about warning signs for cancers in women referred to health centers affiliated with bushehr university of medical sciences. 2. 2016;1(1):30-9.

15. Jamali, C. et al., 2010. awareness of the warning signs of cancer and its risk factors in the population over 18 years old Tehran University of Medical Sciences, 2010. Volume 17 (4), p. 296-307.

16. Christou A, Thompson SC. Colorectal cancer screening knowledge, attitudes and behavioural intention among Indigenous Western Australians. BMC Public Health. 2012;12(1):528.

17. Omran S, Ismail AA. Knowledge and beliefs of Jordanians toward colorectal cancer screening. Cancer nursing. 2010;33(2):141-8.

18. Moattari M, Rouzitalb M, Saber Firoozi M, Zare N. The effect of educational intervention on the knowledge and participation of administrative health personnel in colorectal cancer screening program at Shiraz University of Medical Sciences Shiraz 2003. J Res Med Sci 2009;33(1):47-54.

19. Power E, Simon A, Juszczyk D, Hiom S, Wardle J. Assessing awareness of colorectal cancer symptoms: measure development and results from a population survey in the UK. BMC cancer. 2011;11
(1):366.

20. Al Wutayd O, Alamri F, Ali AM, Kassim KA, Ibrahim AK. Colorectal cancer risk factors: a study of knowledge, attitude and practice among adults in Riyadh, Saudi Arabia. Cancer Research Journal. 2015;3(5):94-9.

21. Robb K, Stubbings S, Ramirez A, Macleod U, Austoker J, Waller $\mathrm{J}$, et al. Public awareness of cancer in Britain: a population-based survey of adults. British Journal of Cancer. 2009;101(S2):S18.

22. Sharifirad, G. Hazave, M.M. Hassanzadeh, A. et al. Effect of health education based on health belief model on preventive measures of smoking in school, 2008.10 (1), S.79- 86.

23. Harmy M, Norwati D, Noor NM, Amry A. Knowledge and attitude of colorectal cancer screening among moderate risk patients in West Malaysia. Asian Pac J Cancer Prev. 2011;12 (8):1957-60.

24. Wang M-Y, Lin G-Z, Li Y, Dong H, Liao Y-H, Liu $\mathrm{H}-\mathrm{Z}$, et al. Knowledge, Attitudes, Preventive Practices and Screening Intention about Colorectal Cancer and the Related Factors among Residents in Guangzhou, China. Asian Pacific journal of cancer prevention: APJCP. 2017;18(12):3217.

25. Mansour-Ghanaei A, Joukar F, Mansour-Ghanaei F, Rasoulian J, Naghipour MR, Fani A, et al. Knowledge about colorectal cancer in northern iran: A population-based telephone survey. Asian Pac J Cancer Prev. 2015;16(17):7831-6.

26. Salimzadeh H, Bishehsari F, Delavari A, Barzin G, Amani M, Majidi A, et al. Cancer risk awareness and screening uptake in individuals at higher risk for colon cancer: a cross-sectional study. BMJ open. 2016;6(12):e013833.

27. Sanderson PR, Weinstein N, Teufel-Shone N, Martínez ME. Peer reviewed: assessing colorectal cancer screening knowledge at tribal fairs. Preventing chronic disease. 2011;8(1).

28. $\mathrm{Su}$ TT, Goh JY, Tan J, Muhaimah AR, Pigeneswaren Y, Khairun NS, et al. Level of colorectal cancer awareness: a cross sectional exploratory study among multi-ethnic rural population in Malaysia. BMC cancer. 2013;13 (1):376.

29. Panic N, Leoncini E, Di Giannantonio P, Simone B, Silenzi A, Ferriero AM, et al. Survey on knowledge, attitudes, and training needs of Italian residents on genetic tests for hereditary breast and colorectal cancer. BioMed research international. 2014;2014.

30. Taha H, Jaghbeer MA, Shteiwi M, AlKhaldi S, Berggren V. Knowledge and perceptions about colorectal cancer in Jordan. Asian Pac J Cancer Prev. 2015;16(18):8479-86.

31. Wong MC, Hirai HW, Luk AK, Lam TY, Ching JY, Griffiths SM, et al. The knowledge of colorectal cancer symptoms and risk factors among 10,078 screening participants: are high risk individuals more knowledgeable? PloS one. 2013;8(4):e60366.

32. Bhurgri H, Gowani SA, Itrat A, Samani S, Zuberi A, Siddique MS, et al. Awareness of cancer risk factors among patients and attendants presenting to a 
tertiary care hospital in Karachi, Pakistan. Journal of the Pakistan Medical Association. 2008;58(10):584.

33. Puri S, Mangat C, Bhatia V, Kaur A, Kohli D. Knowledge of cancer and its risk factors in Chandigarh, India. Int J Epidemiol. 2010;8(1).

34. Sessa A, Abbate R, Di Giuseppe G, Marinelli P, Angelillo IF. Knowledge, attitudes, and preventive practices about colorectal cancer among adults in an area of Southern Italy. BMC cancer. 2008;8(1):171.

35. Zubaidi AM, AlSubaie NM, AlHumaid AA, Shaik SA, AlKhayal KA, AlObeed OA. Public awareness of colorectal cancer in Saudi Arabia: A survey of 1070 participants in Riyadh. Saudi journal of gastroenterology: official journal of the Saudi Gastroenterology Association. 2015;21(2):78.

36. Mosli MH, Al-Ahwal MS. Colorectal cancer in the Kingdom of Saudi Arabia: need for screening. Asian Pacific Journal of Cancer Prevention. 2012;13 (8):3809-13.

37. Puteh SEW, Khairudin SNA, Kabinchong C, Musa N, Joo CK, Saad NM, et al. Relationship of Knowledge, Attitude, Practice (KAP) and Demographic factors with quality of life among urban colorectal cancer patients in Malaysia. Middle East Journal of Cancer. 2014;5(1):31-40.

38. Ravichandran K, Al-Hamdan NA, Mohamed G. Knowledge, attitude, and behavior among Saudis toward cancer preventive practice. Journal of Family and Community Medicine. 2011;18(3):135.

39. Chong VH, Lim AG, Baharudin HN, Tan J, Chong CF. Poor knowledge of colorectal cancer in Brunei Darussalam. Asian Pac J Cancer Prev. 2015;16:3927 -30 .
40. Shouri Bidgoli AR, Taheri Kharame Z, Asayesh H, Sharififard F, Sheydaiyan Arani M, Hajaligol A, et al. A Study of Knowledge, Attitude, and PracticeonColorectal Cancer Screening among Individuals Older than50 Years Based on Health Belief Model. Qom Univ Med Sci J. 2015;9(1):5965.

41. Woudstra AJ, Dekker E, Essink-Bot ML, Suurmond J. Knowledge, attitudes and beliefs regarding colorectal cancer screening among ethnic minority groups in the $\mathrm{N}$ etherlands-a qualitative study. Health Expectations. 2016;19(6):1312-23.

42. Meissner HI, Yabroff KR, Dodd KW, Leader AE, Ballard-Barbash R, Berrigan D. Are patterns of health behavior associated with cancer screening? American Journal of Health Promotion. 2009;23 (3):168-75.

43. Greiner KA, Born W, Nollen N, Ahluwalia JS. Knowledge and perceptions of colorectal cancer screening among urban African Americans. Journal of general internal medicine. 2005;20(11):977-83.

44. Abdullah M, Fauzi A, Syam AF, Makmun D, Simadibrata M, Manan C, et al. Hospital-based survey on knowledge and attitude toward colorectal cancer screening among Indonesian population. Indonesian Journal of Gastroenterology, Hepatology, and Digestive Endoscopy. 2009;10:515. 